\title{
LA OPINIÓN PÚBLICA IBÉRICA HOY. UN ANÁLISIS DE CONJUNTO A TRAVÉS DEL BARÓMETRO HISPANO-LUSO
}

\section{IBERIAN PUBLIC OPINION TODAY. AN OVERALL ANALYSIS THROUGH THE HISPANO-LUSO OPINION POLL}

AUTOR

Pablo Hernández Ramos: Investigador-Doctorando. Facultad de Ciencias de la Información. Universidad Complutense de Madrid. Madrid (España)

pablohr@ccinf.ucm.es

\section{RESUMEN}

El Barómetro de Opinión Hispano-Luso es una herramienta de análisis de opinión que refleja las posiciones de la ciudadanía ibérica en torno a diferentes temas de actualidad. La opinión pública ibérica, entendida como un agregado de la opinión pública portuguesa y la opinión pública española, muestra una dirección de pensamiento clara -pero con ciertos matices-, favorable a la cooperación ciudadana e institucional y refractaria a posibles experimentos de unión política.

\section{PALABRAS CLAVE}

España, Portugal, nacionalismo, opinión pública

\section{ABSTRACT}

The Hispanic-Lusitanian Opinion Poll (Barómetro de Opinión Hispano-Luso) is an annual survey that reflects the positions of the Iberian citizens around several current issues. The Iberian public opinion, understood as an aggregate of the Portuguese public opinion and the Spanish public opinion, shows a clear direction of its thinking, in favor 
of an increase of the cooperation between citizens and institutions and opposed to potential political union experiments.

\section{KEY WORDS}

Spain, Portugal, nationalism, public opinion

\section{ÍNDICE}
$\boldsymbol{1}$ 1. INTRODUCCIÓN
$\boldsymbol{\kappa}$ 2. UN POCO DE HISTORIA
$\boldsymbol{\sim}$ 3. ANÁLISIS DEL BOHL
- 3.1. Vecinos bien avenidos, pero unos más que otros
b 3.2. Economía, infraestructuras y seguridad
3.3. Cooperación ibérica
b. 3. El portuñol en las aulas
3.5. El sueño de iberia
3.6. En torno al conocimiento mutuo
$\boldsymbol{\sim}$ 4. CONCLUSIONES
$\boldsymbol{\sim}$ 5. BIBLIOGRAFÍA DE REFERENCIA
$\boldsymbol{c}$ 6. WEBGRAFÍA

\section{INTRODUCCIÓN}

"Não sou profeta, mas Portugal acabará por integrar-se na Espanha". Esta frase, pronunciada en julio de 2007 por José Saramago en una entrevista concedida al lisboeta Diário de Noticias $^{1}$, devolvió a la primera fila del panorama mediático una vieja cuestión que para unos es una bella utopía, para otros un engorroso problema y para algunos una terrible ofensa. Dicha cuestión es la posibilidad de la unión política de España y Portugal, que despierta muchas y muy diferenciadas reacciones y se inscribe en una corriente sociocultural más amplia: el iberismo, movimiento cultural y político impulsado durante el siglo XIX por pensadores lusos como Latino Coelho o Henriques ${ }^{1}$ Consultar Webgrafía. 
Nogueira y por políticos españoles como Andrés Borrego o Sinibaldo de Mas, y que en ocasiones se ha identificado con una ideología nacionalista, una de cuyas metas sería la creación de un solo Estado sobre el suelo ibérico.

Como es sabido, durante el Novecientos se vivió una explosión sin parangón de las ideologías nacionalistas: potencias europeas de largo recorrido como Austria-Hungría y el Imperio Otomano sufrieron movimientos rupturistas procedentes de regiones con identidades "propias"2, en su momento justificadas por la existencia de viejas instituciones medievales y/o de lenguas diferentes a la oficial. España, que ya había perdido su condición de potencia europea, vivió a finales de siglo el ascenso del catalanismo y del nacionalismo vasco. También existieron ejemplos de nacionalismos de carácter centrípeto, es decir, tendentes a la unificación de varias entidades políticas que se habían mantenido separadas. Los ejemplos más descollantes en Europa, culminados con enorme éxito, son el italiano y el alemán, pero solemos olvidarnos de que Bolívar y San Martín tuvieron en América del Sur sueños de unificación parecidos. En la antigua América española, y pese al fracaso de los nacionalismos centrípetos, las elites criollas estaban configurando desde principios de siglo Estados liberales basándose en los nuevos conceptos de pueblo, soberanía y nación surgidos de la Revolución Francesa y de la Independencia de los Estados Unidos de América.

Pues bien, en este contexto de éxito de los programas nacionalistas, el nacionalismo iberista fue de los pocos que no disfrutó de un triunfo práctico, coincidiendo así de manera clamorosa con los demás nacionalismos surgidos en la Península Ibérica. Ni siquiera el nacionalismo español ha conseguido un triunfo pleno en sus doscientos años de existencia, edad de que goza esta ideología si consideramos que el nacionalismo español moderno fue naciendo al mismo tiempo que los súbditos de los Borbones se enfrentaban a las tropas de Napoleón entre 1808 y 1814 (Álvarez Junco, 2001: 129).

2 Las comillas se refieren a la inseguridad de la noción de "propiedad". ¿En base a qué argumento se arroga una nación, una región, un pueblo, un país, la propiedad de una lengua o de unas instituciones? 
Ciertamente el nacionalismo español -mal llamado español, puesto que es de matriz castellanista-, siendo intrínsecamente débil y teniendo una escasez severa de razones sólidas para consolidar un Estado unido, es junto con el portugués el único de la Península que ha sabido hacerlo y lo que es más, mantenerlo en el tiempo. Pero tan cierto como esto es que en lugares como el País Vasco o Cataluña el nacionalismo español está prácticamente desaparecido o muy desgastado, siendo sus sustitutos naturales los nacionalismos particulares de cada región, que trasladan el discurso nacionalista a los círculos de derechas, católicos, empresariales o pseudoizquierdistas, según el caso, cambiando la etiqueta del terruño grande por la del pequeño. Pese al poder electoral que tienen en España los llamados nacionalismos periféricos, tanto los de derechas como los supuestamente de izquierdas, en ningún caso han podido o sabido organizar un movimiento lo suficientemente sólido como para plantar cara de verdad al Estado español. Más bien han sido partícipes, siempre que han tenido oportunidad, de las oportunidades que el Estado les ha brindado para consolidar sus postulados y su ideología en torno a la nación correspondiente, a mayor gloria de sus mandatarios.

En definitiva, en la actualidad el único nacionalismo relativamente fuerte presente en la Península Ibérica es el portugués, que ejemplifica a la perfección la cara oscura de esta ideología anacrónica, oponiéndose sistemáticamente a todo aquello que huela a español y agitando el fantasma de la conquista (?), como demostró en la última campaña electoral Manuela Ferreira Leite, candidata del Partido Social Demócrata (conservador): Leite prometió suspender las obras del tren de alta velocidad Madrid-Lisboa, pensando más bien en los votos que ello le reportaría que en los beneficios que los ciudadanos y la economía portuguesa pudieran sacar de dicha infraestructura. Uno de los argumentos 
más utilizados por Ferreira Leite fue el de que Portugal "no es una provincia española" 3 .

Las élites nacionalistas portuguesas siempre han aprovechado el impulso que les proporcionaban tanto el supuesto peligro español como la temida unificación ibérica para ganar adeptos entre la población y consolidar así las estructuras de poder. Este impulso político, basado en el rechazo al Otro y en el irracional orgullo por lo "propio" inseparable de cualquier nacionalismo, ha estado presente de manera continuada en Portugal como reacción a "lo ibérico", como manifestaba en una entrevista el profesor de la Universidade de Lisboa y especialista en nacionalismo portugués Sergio Campos Matos: “O iberismo teve a contrario uma função relevante na construção de uma certa identidade nacional portuguesa. Teve uma influência social escassa, mobilizou um pequeno grupo de intelectuais e políticos. Mas suscitou uma profunda reacção nacionalista por parte de uma elite política e intelectual em Portugal" 4 . Creo que no se hace necesaria una traducción de estas palabras, que enseñan cómo y por qué el nacionalismo portugués siempre ha gozado de relativa buena salud: la construcción del enemigo exterior nunca ha resultado complicada y la simple mención de "España" o "Iberia" generaba instantáneamente una reacción nacionalista.

Frente a este panorama reductor de realidades diversas, que están ahí y que siempre estarán, por mucho malabarismo terminológico que se haga con determinadas palabras (pueblo, nación, país) que cambian de significado según quién las pronuncie, el iberismo siempre se alzó como un antídoto contra los nacionalismos particulares, quizá sin que sus teóricos se dieran cuenta de que ese movimiento escondía en sí mismo no pocas dosis de lo mismo. 


\section{UN POCO DE HISTORIA}

Se suele afirmar, erróneamente, que España y Portugal estuvieron unidos bajo la corona de los Felipes durante el periodo comprendido entre 1580 y 1640 . No es cierto, sin embargo, puesto que existe un matiz que adquiere importancia superior cuando se toma en cuenta, y es que dicha unión -así como la configuración general del imperio de los Habsburgo- era de carácter dinástico y no político. Es decir, las coronas se mantuvieron separadas aunque estuvieran ceñidas sobre la misma cabeza.

Partiendo, pues, de la base de que nunca en la Historia estuvieron unidas políticamente España y Portugal, algunos autores consideran que el momento más propicio para que esa unión se llevara a cabo fueron las Cortes de Cádiz. Durante las fechas previas al proceso constituyente de 1812, los sectores absolutistas propusieron como regente a la infanta Carlota Joaquina, hermana de Fernando VII y esposa del regente portugués João de Bragança, quien posteriormente reinaría como João VI. La consumación de este proyecto hubiera supuesto la coincidencia del matrimonio en las dos regencias, regresando de este modo los territorios ibéricos a una situación similar a la de la época filipina, y con perspectivas de futuro. Sin embargo, las facciones liberales, tanto españolas como portuguesas, a pesar de juzgar con complacencia esa posibilidad, prefirieron anteponer los intereses de su ideología a la cuestión nacional y no permitir al absolutismo retomar el poder (Rocamora, 1994: 28).

Para no extendernos demasiado en los episodios históricos relacionados con el iberismo, lo que nos alejaría del objeto de este artículo, debemos saltar varias décadas en el tiempo y trasladarnos hasta septiembre de 1868, cuando en España estalla la revolución que acabaría con el reinado de Isabel II y en Portugal se suceden las crisis políticas. Las fechas posteriores a la Gloriosa fueron, en mi opinión, el punto álgido del movimiento iberista. Durante el Sexenio Democrático, la propagación de movimientos políticos considerados marginales en España hasta ese momento fue explosiva y la 
inestabilidad política contribuyó, para bien y para mal, a la difusión de corrientes de todo tipo. Las tendencias políticas que durante el siglo XIX se adscribieron a la corriente iberista estaban localizadas en la izquierda del espectro político, tanto en la vertiente republicana como en la monárquica. Sin embargo, tras el fracaso de la monarquía de Amadeo I y de la primera experiencia republicana española, el regreso de la monarquía borbónica fue un punto de no retorno para el iberismo como ideal realizable (Rocamora, 1994: 110). Durante el resto del siglo XIX, Portugal y España siguieron siendo amables vecinos y poco más.

El paso al siglo XX mostraba a una España buscándose de nuevo a sí misma y a un sistema político portugués en pleno proceso de descomposición, que culminaría en 1910 con la proclamación de la Primera República. A partir de los años 20, la dictadura sería el modelo elegido (o impuesto) en ambos países, con el paréntesis de los cinco años republicanos en España. Tanto Primo de Rivera y Franco, por parte española, como Salazar, por parte portuguesa, no tuvieron ni el más mínimo interés en retomar la tradición iberista. Las relaciones hispano-portuguesas siguieron el camino de la cordialidad esperada entre dos dictaduras de similar origen ideológico. Con el fin del salazarismo y del franquismo, que como la mayoría de los hechos históricos decisivos para Portugal y España sucedieron prácticamente de manera paralela en el tiempo, llegó la apertura hacia Europa y la consiguiente entrada en la Comunidad Económica Europea. Casualmente o no, los Estados ibéricos se incorporaron a la CEE el mismo día, el 1 de enero de 1986.

La Unión Europea hoy, incluso con todos sus fallos y su relativa inoperancia, sigue siendo la alternativa más sugerente y la siguiente estación en la evolución de los Estados modernos consolidados tras la revolución de 1789, si es que Europa quiere seguir teniendo poder para influir sobre el conjunto de la política, de la economía y de la sociedad mundial. El iberismo hoy debe entenderse, pues, no como una aspiración a la unión política de Portugal y España, sino como la necesidad de consolidación de un 
poder fuerte y estable en el sur de Europa, que además tenga una influencia innegable tanto en el ámbito regional europeo como en el mediterráneo y en el americano. Sin embargo, en las sociedades ibéricas sigue habiendo ciertos sectores que no olvidan la posibilidad de la unión, y que incluso la defienden, y eso es, entre otras cosas, lo que saca a la luz el Barómetro de Opinión Hispano-Luso.

\section{ANÁLISIS DEL BOHL}

El Barómetro de Opinión Hispano-Luso (en adelante BOHL) es un instrumento de medición del estado de la opinión pública en España y Portugal, que ha sido realizado en dos ocasiones (2009 y 2010) por el Centro de Análisis Sociales de la Universidad de Salamanca con el apoyo del Instituto Superior de Ciências do Trabalho e da Empresa, perteneciente al Instituto Universitário de Lisboa. Citando a los propios autores, el BOHL es "un estudio de opinión pública que busca obtener un flujo de información sistemática sobre la opinión que existe en España y Portugal en relación a problemas y temáticas que afectan a ambos países" ${ }^{2}$. Yo me permito añadir que es un instrumento valiosísimo para analizar el estado en que se encuentra la opinión pública ibérica, no solo en torno a las cuestiones sociales que afectan a Portugal y España en el presente, sino también en torno a posibles escenarios políticos futuros, más o menos imaginativos.

\subsection{VECINOS BIEN AVENIDOS, PERO UNOS MÁS QUE OTROS}

En cuanto a la percepción general de las relaciones entre ambos países, la opinión pública ibérica reflejada a través del BOHL emite un juicio claramente positivo. Dos de cada tres ciudadanos ibéricos se mostraron convencidos en 2009 de que las relaciones entre Portugal y España eran buenas o muy buenas. Esta opinión creció en 2010 hasta englobar a las tres cuartas partes de la población. Así, a grandes rasgos, se puede

${ }^{5}$ Consultar Webgrafía 
afirmar que en el día a día, españoles y portugueses nos vemos como amigos sin ninguna duda de ello. Sin embargo, hay dos grupos de relativa importancia que no opinan del mismo modo. Más del 20\% de los portugueses considera que las relaciones entre los dos Estados peninsulares son "regulares". El BOHL no solo se ha ocupado del estado de las relaciones hispano-portuguesas en el momento presente, sino que también ha investigado sobre la percepción que tienen portugueses y españoles sobre la evolución de las relaciones entre ambos países en los últimos años. A este respecto, la diferencia de percepciones entre las dos ciudadanías es más que notable. Mientras que la mayoría de los españoles (51\% en 2009, 64\% en 2010) piensan que las relaciones entre ambos países se han mantenido en un mismo punto, más de la mitad de los portugueses han percibido mejoras.

Uno de los aspectos más importantes del BOHL es el referido a los problemas comunes que afectan al territorio ibérico. Los conflictos que trata el Barómetro tienen una clara correspondencia en el contexto europeo, de ahí que un análisis de cómo se afronten los problemas en España y Portugal puede servir como modelo para toda la Unión. En primer lugar, el aprovechamiento y utilización del agua de los ríos se revela como un aspecto problemático para una gran mayoría de portugueses, rozando el $70 \%$ según datos de 2009. Es una postura completamente lógica, teniendo en cuenta que Portugal no tiene apenas ríos importantes que nazcan dentro de sus fronteras (excepción hecha del Mondego). Por desgracia, la contaminación fluvial es cada vez mayor, y si esto es un problema dentro de las propias Confederaciones Hidrográficas españolas, entre localidades que soportan una contaminación fluvial que se arrastra desde varias decenas de kilómetros río arriba, no podía ser una cuestión que dejara indiferentes a los portugueses. No obstante esto, la utilización y aprovechamiento de los ríos es también una cuestión que preocupa a los españoles. En 2009, un 30\% de los encuestados en España pensaba que este asunto era "bastante problemático", aunque en 2010 este porcentaje bajó hasta el $23 \%$. 
El segundo de los problemas de los que se ocupó el BOHL fue el de la delimitación de las fronteras, cuestión a la que se da mucho bombo desde ciertos sectores políticos y mediáticos cuando interesa dar publicidad -sea para bien o para mal- a los mensajes nacionalistas portugueses más radicales ("Devolvam-nos Olivença!”). Visto (o supuesto) el orgullo portugués por su tierra y las reacciones del nacionalismo rancio cuando surge el tema de las fronteras, nadie diría que casi un 70\% de los portugueses consideran que la delimitación de las fronteras es un asunto "nada problemático". De hecho, son veinte puntos más que el resultado español, que roza el 50\%. Al lector incrédulo le bastaría con darse un paseo por los pueblos fronterizos de Galicia, Zamora o Badajoz para comprobar cuánto de cierto tienen estas cifras. En esas zonas incluso se quedarían cortas, ya que el hecho de la vida en común a ambos lados de la Raya está tan normalizado que es posible hablar de pueblos prácticamente unidos. Como bien se afirma en el propio Barómetro de Opinión Hispano-Luso de 2009, "la delimitación de fronteras no es una cuestión que origine conflicto. Tanto españoles como portugueses consideran que es un asunto de importancia menor" 6 .

\subsection{ECONOMÍA, INFRAESTRUCTURAS Y SEGURIDAD}

El tercer asunto tratado en el epígrafe "Problemas comunes" es el de las inversiones empresariales. De nuevo una cuestión ibérica que tiene reverberaciones europeas. No se descubre nada nuevo diciendo que uno de los ámbitos en los que la integración europea ha tenido más éxito es en el de la libre circulación de capitales. Y parece que en el terreno peninsular las inversiones empresariales en el país vecino (sea del lado que sea) también gozan de popularidad. Un 61\% de portugueses y un 51\% de españoles consideraban en 2009 que este asunto era "poco o nada problemático". Sin embargo, en esta ocasión no se puede prescindir de la mención al 19\% de portugueses que consideran las inversiones españolas como una cuestión "bastante o muy problemática". Parece, a la vista de estos datos, que desde el otro lado de la Raya se

\footnotetext{
${ }^{6}$ Consultar Webgrafía
} 
teme bastante más el "imperialismo" económico que la presión política sobre las fronteras, percibida de manera clara como una cuestión del pasado.

A continuación, el BOHL pasa a ocuparse de las comunicaciones, tanto por ferrocarril como por carretera. Es en este punto donde la percepción del problema por parte de los españoles es más negativa. El porcentaje de encuestados españoles que ven las comunicaciones como "muy problemáticas" o "bastante problemáticas" es del 20\%, doblando así el porcentaje de portugueses que piensan lo mismo. Más de la mitad de la población lusa piensa, según, el BOHL, que la red de carreteras y ferrocarriles ibérica no es "nada problemática". En 2010 se subdividió este apartado de la encuesta en dos series de preguntas diferentes, y los datos permiten llegar a una conclusión clara: existe un profundo desconocimiento por ambos lados de la frontera respecto a la situación de la red ferroviaria, puesto que casi la mitad de los españoles y más del 30\% de los portugueses o bien no respondieron o bien no tenían una opinión formada cuando se les consultó por el tema en cuestión.

En el quinto y último punto de la encuesta sobre los problemas comunes se estudia la preocupación de los ciudadanos respecto al refugio de delincuentes o terroristas al otro lado de sus fronteras. En 2009, los porcentajes de preocupación eran altos, llegando al 64\% entre los portugueses y al 51\% entre los españoles, pero en 2010 esa preocupación se disparó hasta casi el $80 \%$ entre los ciudadanos lusos, mientras que en España tres de cada cuatro encuestados consideraron que esta cuestión era de alguna manera problemática. Esta tendencia claramente al alza tiene que ver probablemente con la detención en Portugal de dos miembros de ETA, hecho acontecido en enero de $2010^{7}$ y que tuvo una segunda parte con el descubrimiento de un piso franco en febrero y una detención más en el mes de marzo $^{8}$. A partir de ese momento, la preocupación de la 
opinión pública ibérica por la posibilidad de que algunos miembros del grupo terrorista estuvieran buscando refugio en Portugal creció de manera destacada.

Así, vemos cómo la opinión pública ibérica mantiene puntos de vista relativamente similares en ambos países en torno a sus problemas comunes, aunque existen puntos de fricción importantes, sobre todo en lo referente al uso y aprovechamiento de los ríos. El aspecto más preocupante que deja entrever el BOHL es el alto porcentaje de encuestados españoles -siempre en torno al $20 \%$ - que no saben o no quieren contestar a las cuestiones planteadas por el Barómetro. Esto revela o bien desconocimiento o bien desinterés por las cuestiones relativas al presente y futuro de las relaciones ibéricas, algo que solo puede repercutir de manera negativa a la hora de buscar posibles soluciones para los problemas que se han enunciado.

\subsection{COOPERACIÓN IBÉRICA}

Una vez analizada la percepción de la opinión pública ibérica en torno a los problemas comunes entramos en el terreno político, a priori el más atractivo. Los responsables de BOHL optaron por preguntas sobre cinco ámbitos muy concretos y realistas sobre los cuales cabría la posibilidad de un acercamiento en las políticas de los dos Estados ibéricos. La consulta se hizo sobre los siguientes puntos: la homogeneización del sistema fiscal, la supresión de las restricciones a la movilidad y el asentamiento de profesionales, trabajadores y empresas, la presentación de candidaturas conjuntas para eventos internacionales, la posibilidad de una mayor colaboración policial, judicial y militar y, por último, la posibilidad de una reunión trimestral de los gobiernos. Pues bien, en todos los apartados excepto uno existe una mayoría clara de personas que están a favor de la cooperación hispano-portuguesa. En cuanto a las respuestas de los encuestados españoles, una abrumadora mayoría (en torno al 90\%) está a favor de una mayor colaboración policial, judicial y militar con Portugal. Esta cifra revela una preocupación real por los problemas de orden público y de seguridad que puedan 
repercutir en la vida cotidiana de los ciudadanos, y que puedan ser amortiguados o incluso suprimidos si se incrementa dicha colaboración.

El resto de respuestas, como he afirmado antes, arroja mayorías claras en todas las cuestiones consultadas, excepción hecha de la propuesta de homogeneización del sistema fiscal. En este punto es donde los españoles se muestran menos favorables a una cooperación con Portugal. Pese a que el porcentaje de personas favorables a una unificación de los sistemas fiscales creció un 3\% en 2010 (el 40\%, frente al 37\% de 2009), también creció el porcentaje de personas en contra, llegando a ser mayoría (41\%) frente a las que propugnaban la homogeneización. Pese a este dato, ciertamente negativo de cara a una posible puesta en común de las políticas fiscales, hubo fuertes crecimientos entre la población española favorable a la supresión total de las restricciones a la movilidad y asentamiento de profesionales y empresas (pasó de un 63\% a un 76\%) y se registró también un crecimiento notable entre las personas favorables a una reunión trimestral de ambos gobiernos en pleno, llegando en 2010 a las tres cuartas partes de la población, una cifra ciertamente importante.

Pero si la estadística nos ofrece un posicionamiento claro de los ciudadanos españoles a favor de las propuestas de cooperación -exceptuando la unión fiscal-, en Portugal estas cifras se disparan: en 2010 más del 80\% de los portugueses estaban a favor de una mayor cooperación con España, volviendo a excluir de esta afirmación la propuesta de unificación de las políticas impositivas. Si bien la homogeneización fiscal no llega a esta barrera del $80 \%$, la mayoría de los portugueses se muestra a favor de dicha medida. Y no solo eso, sino que se trata de una mayoría fuerte, que casi triplica a las personas que están en contra.

En 2010 se registraron en Portugal unas cifras extremadamente favorables a las diferentes propuestas de cooperación con el país vecino, certificando un notable aumento en todas ellas respecto a las mismas propuestas de 2009. Así, repasando los 
porcentajes de ese año observamos los siguientes datos: un 65\% de portugueses se muestra favorable a una unificación de las políticas fiscales (subida de un 5\% respecto al año anterior); el 86\% está a favor de la supresión de todas las restricciones a la movilidad de profesionales y empresas, y ese mismo porcentaje también ve con buenos ojos la concurrencia conjunta de ambos Estados para la organización de eventos internacionales; casi el $85 \%$ se muestra partidario de una reunión trimestral de los gobiernos en pleno; por último, prácticamente la totalidad de los ciudadanos lusos (un 94\%) es favorable a una mayor colaboración judicial, policial y militar.

Es en este último punto, el de la colaboración en materia de seguridad, donde el porcentaje español se acerca más al portugués, superando ambos el 90\% de ciudadanos a favor. En Portugal se dibuja, pues, un escenario muy diferente al español, sobre todo en relación a las aplastantes mayorías que están a favor de las actuaciones mutuas, dirigidas al beneficio de ambos países ibéricos. El optimismo con el que se ve en Portugal una posible cooperación con España es digno de ser tratado con mayor amplitud, pero puestos a teorizar -pese a que este no es el lugar más indicado para lanzar hipótesis respecto a las razones de este entusiasmo- es plausible que por el hecho de que España sea el único vecino continental de Portugal los ciudadanos lusos piensen que les irá mejor si trabajan codo con codo con aquellos que tienen más a mano, dejando de lado envidias y posibles roces que no harían sino perjudicar a todos. Si piensan así los portugueses no creo que les falte razón, puesto que la cooperación y la ayuda mutua pueden ser, en estos tiempos de crisis y de falta de horizontes seguros (sobre todo en el ámbito económico), una de las mejores recetas que se pueden administrar, viendo el resultado que están teniendo las políticas favorables a los poderes económicos teóricamente independientes y las perspectivas de un "sálvese quien pueda" para la economía europea.

Además de las propuestas repasadas, en 2010 se añadió al BOHL una nueva pregunta, que hacía referencia a la utilización conjunta de servicios y equipamientos (como 
pudieran ser hospitales, centros para personas mayores, polígonos industriales o estaciones de servicio, entre otros) en municipios o comarcas fronterizas. La tendencia que revelaron las respuestas fue la misma que en las anteriores propuestas: mayorías claras a favor de dicha posibilidad, pero con mayor respaldo por parte portuguesa. Tres de cada cuatro españoles estarían dispuestos a compartir servicios y equipamientos en regiones cercanas a la Raya, mientras que en Portugal esta cifra se dispara hasta sobrepasar el $90 \%$ de personas a favor. Estos datos refuerzan la tendencia a la buena disposición que tienen los ciudadanos de ambos lados de la frontera para cooperar de manera más profunda y continuada en el futuro. Desde luego que los tópicos sobre los temores portugueses a una invasión española (en un sentido metafórico del término) quedan muy en entredicho si hacemos caso a estas abrumadoras mayorías, estos porcentajes sumamente ilustrativos de cómo los intereses de la opinión pública ibérica concurren en muchas ocasiones y gozan de un sustrato común cierto. Ahora bien, cuando pasemos al terreno simbólico observaremos cómo los portugueses ya no tienen posicionamientos tan claros (tampoco los tendrán los españoles).

\subsection{EL PORTUÑNOL EN LAS AULAS}

Antes de entrar en ese terreno tan resbaladizo de los símbolos, queda por repasar otra cuestión, no exenta ni mucho menos de carácter distintivo e identitario, pero también llena de un carácter práctico, como revelan las respuestas de los ciudadanos registradas en el BOHL: dicha cuestión es la lengua, sistema de comunicación digno de la mayor protección en cuanto a herramienta cultural insustituible y preciosa, pero que ni mucho menos es un elemento arcano e intocable cuando bajamos a la arena de la vida cotidiana y de la existencia práctica.

En 2009, la mitad de los portugueses estaba a favor de que el castellano fuera idioma de estudio obligatorio en la escuela primaria y secundaria, frente a un $44 \%$ que estaba en contra. En 2010 las cifras se invirtieron y mientras el 44\% de los ciudadanos lusos se 
declaraban a favor de la enseñanza obligatoria del castellano, casi un 53\% se mostraron en contra. Estamos hablando de un asunto de primera magnitud, puesto que el dominio de la lengua castellana para un niño portugués (y viceversa) no puede constituir un grave retraso en su educación, de acuerdo a las similitudes existentes entre los dos idiomas. Bien al contrario, de modo más que probable le serviría para formarse un nuevo modo de comunicación y de cultura que solo podría sumar en su formación. Podemos interpretar la polarización que muestra la ciudadanía portuguesa a este respecto como una muestra de que la idea está siendo tenida en cuenta a nivel ciudadano. Obviamente, no se puede desdeñar a ese alto porcentaje de personas (más de la mitad en 2010) que se muestran en contra.

Sin embargo, hay un matiz importante que hace pensar que esta postura en contra de la enseñanza obligatoria del castellano no equivale ni mucho menos a una oposición radical a que los niños portugueses aprendan dicho idioma. Los responsables del BOHL introdujeron, acertadamente a mi entender, una pregunta que otorga un valor extra y un elemento interpretativo importante a la primera: cuál es la postura del ciudadano luso respecto a la enseñanza del castellano como lengua optativa en la enseñanza primaria y secundaria. Los porcentajes de respuestas favorables se equiparan en esta ocasión a las preguntas en torno a las propuestas de cooperación, llegando a superar el $85 \%$ de ciudadanos a favor del castellano como optativa. Apenas el $10 \%$ de los portugueses (ciertamente el indestructible nacionalismo radical) estaría en contra de esta posibilidad. Así pues, el “imperialismo" cultural recibe muestras de oposición más claras que el económico, pero si hablamos de la posibilidad de elegir la lengua castellana como opción, sin imposiciones, el grueso de la población portuguesa se muestra claramente a favor.

La situación en España respecto al idioma portugués está mucho más definida, sin que esto suponga, en mi opinión, que sea una mejor situación. En España, donde se arrastra una profunda problemática en torno a la enseñanza de los idiomas cooficiales, no se 
podía esperar una respuesta mayoritariamente favorable a la enseñanza obligatoria del portugués. Sin embargo, incluso teniendo esto en cuenta, los porcentajes de población favorable a esta medida son muy bajos (en torno al 15\%, tanto en 2009 como en 2010). No solo eso, sino que el resto de los encuestados, que podían situarse en una posición más o menos neutral optando por no responder a la pregunta, están, en una aplastante mayoría, en contra de la enseñanza del portugués como lengua obligatoria en los colegios españoles. Un 76\% en 2009, que subió hasta rozar el 80\% en 2010, está en contra de esta propuesta.

Para entender esta postura es preciso enfocar la cuestión (me niego a calificarlo como problema) desde el manido punto de vista identitario. ¿Por qué cerrarse en banda y responder únicamente ante una sola categoría identitaria, si y solo si esta se adscribe a una única lengua? La cooperación y el entendimiento entre Portugal y España, traducido en acuerdos políticos a medio y largo plazo, reforzaría el poder de decisión y la influencia de un teórico poder ibérico en Europa. Esto se podría conseguir de manera mucho más sencilla incrementando en la medida de lo posible el conocimiento de las lenguas de ambos Estados entre ambas ciudadanías. Del mismo modo, las políticas autonómicas y los conflictos que se arrastran en España seguirían otros derroteros si se arrebatara a los nacionalismos periféricos el monopolio de las lenguas cooficiales (monopolio que ellos mismos se han otorgado sin pedir cuentas a nadie) y si se potenciara un mínimo conocimiento, no digo ya el estudio, de dichas lenguas.

Pero esto es harina de otro costal, y además, volviendo al tema que nos ocupa, todavía hay esperanza para el estudio de la lengua portuguesa en España, aunque sea como asignatura optativa. El 67\% de los españoles encuestados se declararon a favor de esta posibilidad el año 2009, cifra que subió más de diez puntos en 2010, hasta el 79\%. Frente a la relativa flexibilidad de pensamiento de esta gran mayoría (casi cuatro de cada cinco españoles verían con buenos ojos la posibilidad de elegir el portugués como optativa en los colegios), cierto grupo de personas de ideas marchitas se muestran en contra incluso 
de aquella posibilidad: casi una cuarta parte de los encuestados en 2009 y el 17\% de los encuestados en 2010. Como principal y evidente conclusión sobre este apartado, vemos cómo en Portugal existe mucha mayor receptividad respecto al idioma castellano que en sentido contrario; es más, las perspectivas de cambio de ideas la ciudadanía española a este respecto no son muy prometedoras. En este ámbito de la relación mutua, la opinión pública ibérica muestra las costuras de sus divisiones más profundas.

\subsection{EL SUEÑO DE IBERIA}

El Barómetro de Opinión Hispano-Luso presenta en sus encuestas una de las cuestiones más apasionantes para todo aquel ciudadano de la Península Ibérica y de los archipiélagos que se preocupe del futuro de su país: se plantea la pregunta de si Portugal y España deberían unirse para conformar un solo Estado. Este viejo sueño de los iberistas del XIX no tendría ciertamente demasiado sentido en una Europa unida. Pero tristemente no podemos decir que Europa esté verdaderamente unida, menos todavía en lo político y menos aún tras la ampliación al Este. Sin embargo, la mera idea de convertir el territorio al sur de los Pirineos (junto con sus archipiélagos) en un solo Estado despierta fantasías similares a las que hacen que los sueños nacionalistas sigan vivos, y hablo ahora tanto de los llamados periféricos como del centralismo españolista de corte castellano. Cualquier nacionalismo, grande o pequeño, nuevo o viejo, mantiene sus aspiraciones como ideales que la comunidad imaginada -la que sea- aspira a conquistar, y en el caso del nacionalismo ibérico, si es que existe, ese ideal primero y nunca conseguido es el de un Estado común.

Pues bien, en 2009 un 30\% de españoles apoyaba la idea de la federación ibérica, frente al $40 \%$ de portugueses que pensaba lo mismo. Ahora bien, otro 30\% de españoles rechazaba esta idea, cifra similar al 34\% de los portugueses que coincidían en su rechazo. En España, el 29\% de las personas se mostraron indiferentes ante la propuesta, frente al $17 \%$ de Portugal. Estas cifras nos hablan de una profunda división y 
polarización de la opinión pública ibérica al respecto de una posible unificación política. Un año después, las cifras en España se mantenían relativamente estables, siendo un $31 \%$ partidario de la unión, un 33\% contrario y un 30\% indiferente. Sin embargo, en Portugal las posturas favorables a la unión crecieron hasta el $45 \%$, el desacuerdo subió hasta casi el 37\% y los indiferentes bajaron hasta el 13,5\%. Es decir, la ciudadanía portuguesa ha condensado sus opiniones en los extremos, lo que demuestra la existencia de un hondo debate en la sociedad durante el año transcurrido entre las dos encuestas.

Si comparamos estos porcentajes, que despliegan la realidad de unas sociedades polarizadas y divididas, con las escandalosas cifras favorables a la cooperación y la ayuda mutua que previamente hemos repasado, vemos la diferencia entre el valor simbólico que se le otorga a la pertenencia a un país y cómo uno se olvida de todo ello para bien- cuando se trata de bajar a la arena práctica de la colaboración en cuestiones puntuales. Esta opinión personal enlaza con una serie de datos referidos a la forma de integración política que los ciudadanos elegirían en el supuesto caso de la formación de un Estado ibérico único. El BOHL ha proporcionado estos datos únicamente en 2010.

Se propusieron tres posibles escenarios de unión política y dos modelos de cooperación, y la posibilidad de otorgar una nota del 0 al 10 según las preferencias de cada encuestado. Pues bien, ninguno de los tres modelos de unión política logró el aprobado, mientras que los dos modelos de cooperación superaron el 6 de nota media. Concretamente, y repasando las notas de menor a mayor, la posibilidad de constituirse como un Estado unitario apenas recibió un 3,30 en España y un 3,82 en Portugal; la propuesta de unión como Estado federal llegó hasta el 3,64 en España y superó por poco el 4 en Portugal. La idea de la confederación, sin embargo, casi convence a los portugueses, que le dan un 4,74 que roza el aprobado (en España se quedó en un 4,12). De estos datos se desprende la importancia que se le da, en ambos países, al sentido de pertenencia a una determinada comunidad, pese a la voluntad de entendimiento y 
cooperación que se deduce de los aprobados altos otorgados a los modelos de alianza política propuestos a continuación. El acuerdo de plenos derechos políticos a los ciudadanos de cada país residentes en territorio del otro, lo que de facto significaría la concesión de la nacionalidad, recibe una nota de 6,61 en Portugal, por el 6,20 que se le otorga en España. La propuesta de formación de una alianza estable como países ibéricos ante la Unión Europea y América Latina recibe también un 6,20 de los ciudadanos españoles, por el 6,14 de los portugueses. Así, vemos cómo en Portugal, por lo general, se concede mayor valor a la posible unión con España, sea del carácter que sea, aunque solo en dos de los cinco posibles escenarios se aprueban estas propuestas.

\subsection{EN TORNO AL CONOCIMIENTO MUTUO}

Otros aspectos menores, aunque también ciertamente reveladores, del estado de la opinión pública ibérica, son los referidos a lo que sabemos los unos de los otros. Y en este aspecto el panorama desconsuela a cualquiera. El reflejo cultural que otorgan estos datos es un desconocimiento masivo de los datos más elementales respecto a la realidad de dos países vecinos. Solo utilizaremos algunos porcentajes, como muestra: únicamente el 1,2\% de los españoles (!) conoce el nombre del primer ministro portugués, frente al $54,2 \%$ de los portugueses que sabe quién es el presidente del gobierno español. El que solo la mitad de los portugueses conozca la identidad de Zapatero es bastante preocupante, al menos desde el punto de vista de la "cultura general", no digamos ya desde el punto de vista de la cultura política. Pero que solo uno de cada cien ciudadanos españoles sepa de quién hablamos cuando hablamos de José Sócrates no refleja el más mínimo interés hispano por los asuntos de Portugal. En respuesta a la pregunta de cuándo se terminaron las respectivas dictaduras en el país vecino, el porcentaje de ignorancia crece hasta el 90\% en España y hasta el 94,5\% en Portugal. Ya por último, parece imposible creer que solo el $42 \%$ de los españoles sepa cuáles son los colores de la bandera lusa, y que únicamente el 55\% de los portugueses 
acierte a responder "rojo y amarillo" cuando le preguntan por los colores de la bandera española, pero efectivamente eso es lo que muestra el BOHL.

En definitiva, más allá de las buenas noticias que recibimos cuando analizamos los datos en torno a la disposición de los ciudadanos para contribuir y participar en el desarrollo y profundización de la cooperación hispano-portuguesa, el profundo desconocimiento que muestra la masa ciudadana sobre aspectos elementales de la realidad del otro anuncia que las decisiones a tomar de cara a la consecución de una colaboración plena, duradera y productiva tendrán que venir acompañados de una ampliación de los horizontes culturales comunes y del conocimiento mutuo. En el punto 3.1. de este estudio vimos que una quinta parte de los portugueses consideraba que las relaciones entre su país y España eran "regulares".

Para finalizar con el análisis, el BOHL de 2010 incluyó un apartado en el que se preguntaba a los encuestados por su opinión respecto a diferentes países europeos, y las respuestas fueron significativas, sobre todo de cara a la posible destrucción de algunos tópicos y al refuerzo de otros. Si hacemos caso de las respuestas recogidas por el BOHL, se destruye en gran parte el tópico del rechazo portugués hacia lo español, ya que el país que más estiman los lusos es, con grandísima diferencia sobre el resto, España. Casi el $80 \%$ de los portugueses tiene una "buena o muy buena" opinión de España frente al escaso 5\% que afirma tenerla "mala o muy mala". Tras España vienen Francia, con un $64 \%$ de opiniones favorables, y Alemania, con un 60\%. Por parte española, sin embargo, se refuerza el tópico de la admiración hacia franceses y alemanes, que superan a los esforzados portugueses, situados en un tercer lugar en cuanto a la percepción positiva de su país. Alemania suma un $76 \%$ de opiniones "buenas o muy buenas", por un $67 \%$ de Francia y un $64 \%$ de Portugal. Estos porcentajes se refuerzan con los que conocemos a través de una pregunta directa sobre el interés en los asuntos del país vecino: dos de cada tres portugueses afirman tener "algo o mucho de interés" por los asuntos españoles, mientras que en España la relación solo llega al 44\%. De hecho, más de la 
mitad de los españoles reconoce que tiene "poco o ningún interés" por lo que acontezca en Portugal, algo que no puede extrañar si recordamos las cifras que hemos visto cuando repasábamos cuestiones concretas como los colores de las banderas o los nombres de los gobernantes.

\section{CONCLUSIONES}

Tras analizar los resultados que arroja el BOHL, tanto en su edición de 2009 como en la de 2010, podemos llegar a dos conclusiones principales. En un plano general, vemos cómo la opinión pública ibérica goza de una base sólida sobre la que arraigar: la existencia de debates sobre los problemas que afectan al común de la ciudadanía ibérica, la voluntad general de llegar a acuerdos sobre dichos problemas (reflejada en las respuestas referidas a la cooperación interterritorial, abrumadoramente positivas) y una visión de conjunto sobre la situación que atraviesan las sociedades española y portuguesa en los asuntos que atañen a ambas. Bien es cierto que los porcentajes de “abstención", es decir, de preguntas a las cuales los ciudadanos no sabían o no querían contestar, son relativamente altos en algunas consultas puntuales. Sin embargo, este matiz no oscurece la relativa solidez con la que se manifiesta la opinión pública ibérica. Se puede afirmar que hay tendencias claramente marcadas en la sociedad ibérica en torno a las posibilidades de cooperación e incluso en lo referente a una posibilidad de unión política -o de colaboración tan estrecha que, de hecho, signifique una unión- en un futuro más o menos lejano.

En segundo lugar, si nos trasladamos a un plano más particular, diferenciando entre las respuestas portuguesas y las españolas, las sensaciones que se transmiten desde la franja occidental de la Península Ibérica son mucho más positivas que las de los vecinos españoles. Portugal se muestra mucho más abierto a la ayuda mutua y a la fusión de ciertos aspectos de ambas sociedades, siempre y cuando, eso sí, se respete la simbología y los sentimientos de pertenencia. 
Un observador receloso podría hablar de una voluntad de acercamiento para aprovecharse de la mejor situación del vecino, quizá sin darse cuenta de que las elites políticas, económicas y sociales de España no sean precisamente un ejemplo de cómo hacer las cosas, de cómo desarrollar una vida pública modélica. Sin embargo, a mí me gusta pensar que desde Portugal se siente verdaderamente la necesidad de una profundización y de una mejora en las relaciones con España, y que dicha necesidad se puede transformar en virtud si sabemos aprovechar la fuerza conjunta de ambas sociedades. Por otra parte, el tópico del desinterés español hacia lo portugués se confirma de alguna manera haciendo caso de lo que nos dicen las cifras del BOHL. Desde luego que para una mejora de las relaciones, que sin ninguna duda nos beneficiarían a todos y cada uno de nosotros, es necesario mostrar al menos una mayor voluntad de acercamiento y preocuparse por lo que ocurre a nuestro lado.

Pese a todo, más allá de desacuerdos en cuestiones puntuales, que pueden y deben ser debatidos y evolucionar positivamente, y más allá también de rechazos frontales a la colaboración hispano-lusa, que probablemente procedan de sectores muy determinados de la sociedad, la sensación que transmite el análisis del BOHL es que la opinión pública ibérica tiene una orientación clara para colaborar codo con codo de cara al futuro. El seguimiento continuado a la evolución del pensamiento de la opinión pública ibérica, que cubre magníficamente el BOHL, procede de la importancia que se le debe conceder a las relaciones entre los dos Estados ibéricos. Una Iberia que, pese a las dificultades actuales, debe desempeñar un papel fundamental en el desarrollo, mejora y consolidación de las instituciones de la UE, que debe emplear todo su nervio para hacerse fuerte en el sur de Europa y para colaborar también con el conjunto del continente, además de cumplir con su papel de enlace con el mundo mediterráneo y con el americano. 


\section{BIBLIOGRAFÍA DE REFERENCIA}

- ÁlvareZ JUNCO, J.: "Mater dolorosa. La idea de España en el siglo XIX". Madrid, 2001. Taurus.

- ANDERSON, B.: "Comunidades imaginadas. Reflexiones sobre el origen y la difusión del nacionalismo". México DF, 1993. Fondo de Cultura Económica.

- BERGANZA, M. R. y RUIZ SAN ROMÁN, J.A. (coords.): "Investigar en comunicación. Guía práctica de métodos y técnicas de investigación social en comunicación". Madrid, 2005. MacGraw-Hill.

- CRESPI, I.: "El proceso de la opinión pública". Barcelona, 2000. Ariel.

- MARTÍN MARTÍN, Teodoro: "El movimiento iberista. Aproximación a la historia de una idea". Madrid, 2009. ASPUR.

- PEDRO VICENTE, A. y DE LA TORRE, H.: "España-Portugal: estudios de historia contemporánea". Madrid, 1998. Editorial Complutense.

- ROCAMORA ROCAMORA, J.A.: "El nacionalismo ibérico. 1792-1936". Valladolid, 1994. Universidad de Valladolid.

- ROJAS TEJADA, A.J., FERNÁNDEZ PRADOS, J.S. y PÉREZ MELÉNDEZ, C.: "Investigar mediante encuestas: fundamentos teóricos y aspectos prácticos". Madrid, 1998. Síntesis.

- VVAA: “España-Portugal: Horizonte 2010". Madrid, 2001. Estudios de Política Exterior.

\section{WEBGRAFÍA}

- Nota 1 (Saramago) http://dn.sapo.pt/inicio/interior.aspx?content_id=661318

- Nota 2 (Ferreira Leite) http://www.rtve.es/noticias/20090913/ave-entre-espanaportugal-enfrenta-socrates-ferreira-leite-plena-campana-electoral/292179.shtml

- Nota 4 (Campos Matos) http://ddd.uab.es/pub/hmic/16964403n2005p393.pdf 
- Nota 5 (BOHL) http:// casus.usal.es/BOHL/index.html

- Nota 6 (BOHL) http:// casus.usal.es/BOHL/index.html

- Nota 7 (ETA) http://www.rtve.es/noticias/20100110/detenidos-portugal-dospresuntos-etarras-tras-abandonar-furgoneta-bomba-zamora/311074.shtml

- Nota 8 (ETA)

http://www.elpais.com/articulo/espana/Detenido/aeropuerto/Lisboa/etarra/And oni/Zengotitabengoa/elpepuesp/20100312elpepunac_1/Tes 